\title{
Quality Assessment of Strengthened Concrete by FRP Laminates using Non-Destructive Testing
}

\author{
W. F. Tawhed, Yasmen R. Elsayed
}

\begin{abstract}
A non-destructive testing program has been designed to evaluate the integrity of the bond strength of plain concrete beams strengthened by Glass Fiber Reinforced Polymer (GFRP) Laminates. A series of concurrent static load and non-destructive testing experiments were carried out in the materials and testing laboratory at the college of engineering, Mataria, Helwan University, Cairo, Egypt.
\end{abstract}

A total of 90 plain concrete standard beam specimens of dimensions $150 \mathrm{~mm} \times 150 \mathrm{~mm} \times 750 \mathrm{~mm}$ were constructed in the laboratory with three different design strength categories $(38,45$, and 50) MPa. The beam specimens were strengthened by externally bonded GFRP laminates with various number of layers namely (3, 5 and 7) layers. In addition, the effect of debonding of the GFRP laminates was investigated by simulating it by variation in voids between concrete and laminates namely, (0, 30 and $60 \%)$. This study investigates the effectiveness of externally bonded GFRP laminates on the flexural strength of plain concrete beams by using Ultrasonic Pulse Velocity (UPV) device before and during loading until failure and their effect on the p-wave velocities. Four-point flexural tests were performed on the concrete beams, strengthened with different layouts of GFRP laminates and different percentage of voids at the concrete-laminate interface. The capacity of the beams and p-wave velocity were investigated.

It was found that as the percentage of voids decreased, the capacity of strengthened concrete beams increased linearly. The reduction in voids enhanced the beam flexural behavior and controlled tension crack propagation. In addition, it was observed that use of GFRP laminates were more effective with higher concrete characteristic strength provided that debonding is not present. Finally, it was evident that the UPV technique was successful in detecting the variation in concrete p-wave velocity with strength and laminate layers variation.

KEYWORDS: FRP Laminates; FRP strengthening; Laminates debonding; Non-destructive testing; UPV testing

\section{INTRODUCTION}

Strengthening of reinforced concrete structures by externally bonded FRP systems is now a widely accepted technique [1]. However, the use of bonding techniques always implies following installation procedures as presented in the Egyptian Code of Practice (ECP) [2] or the American

Revised Manuscript Received on February 05, 2020.

* Correspondence Author

Waleed F. Tawhed*, Civil Engineering Department, Helwan University, Cairo, Egypt. Email: waleed.tawhed@m-eng.helwan.edu.eg

Yasmen R. Elsayed, Civil Engineering Department, Helwan University, Cairo, Egypt. Email: yasmenramdan2008@yahoo.com

(C) The Authors. Published by Blue Eyes Intelligence Engineering and Sciences Publication (BEIESP). This is an open access article under the CC BY-NC-ND license (http://creativecommons.org/licenses/by-nc-nd/4.0/)
Concrete Institute (ACI) [3]. To ensure, both, long-term performance and durability of FRP reinforcements, application must be as per the standard installation procedures.

The presence of debonding can significantly affect the structural performance and durability of the strengthening systems. Defects should be detected, located and evaluated in order to estimate if replacement is needed. In these conditions, checking of the bonded overlays through in situ by non-destructive evaluation (NDE) techniques is more suitable. The quality-control program should involve a set of specified inspections and tests.

In this research work, non-destructive testing is utilized to evaluate the integrity of a total of ninety concrete beams strengthened by GFRP laminates of these specimens, nine were control beams. Load-testing (destructive) was performed in conjunction with the non-destructive testing to verify and correlate the results. In this study, the specimens were evaluated in the laboratory using the ultrasonic-pulse velocity method to evaluate their initial condition and assess the progression of damage when subjected to load tests in the laboratory. UPV tests were performed before and after the loading sequence for each beam. Correlations between the UPV and load-test results were established in a form of a family of curves that were useful in tracking the progression of damage due to increase in delamination. Finally, the results obtained from the loading tests were used to determine the energy absorption and the stiffness improvement index of the specimens due to strengthening by GFRP sheets.

\section{OBJECTIVES}

This research article presents the results of an assessment of the behavior of concrete beams strengthened by GFRP laminates under four-point load concurrent with a non-destructive test using UPV. The objectives set forth for this research effort are:

1. to examine the physical and mechanical properties of locally constructed GFRP laminates in the laboratory.

2. to investigate the bond strength of externally bonded GFRP laminates to concrete by applying different \% delaminations (voids) at GFRP-concrete interface.

3. to evaluate the efficiency of strengthening by different number of GFRP layer laminates.

4. to determine the sensitivity of the UPV technique to changes in the composite structure due to increase in stiffness by GFRP layers. 
5. to evaluate the accuracy of the UPV technique in detection of the extent of bond strength loss with delaminations.

\section{RESEARCH SIGNIFICANCE}

As strengthening and retrofit of concrete structures by FRP composites in the form of externally bonded reinforcement continue to gain acceptance, the need for monitoring the performance of these structures increases. The overall response of these structures, the used FRP laminate condition and the integrity of the interfacial bond between FRP and concrete all need to be evaluated. As visual inspection might be convenient and effective for external defects, but it is qualitative and subjective. On the other hand, ultrasonic techniques provide a viable methodology capable of assessing both surface and deep subsurface discontinuities. Thus, applying non-destructive methods will provide a comprehensive evaluation tool of the structural condition and service life for concrete structures.

\section{BACKGROUND}

\section{A. FRP Basics}

The quality of an FRP rehabilitation system is highly affected by its integrity, which includes the composite and the adhesive layer in the case of bonded strip, and the composite and the impregnating polymeric resin in the case of dry sheets and fabrics. The interface between the FRP composite and the concrete substrate transfers the loads from the concrete to the FRP composite. Potential defects in FRP composites could also affect the quality of the rehabilitated structures. The presence of such defects as voids, improper cure, debonds and delaminations is almost common during the manufacture and installation of the composite systems. The general effects of potential defects on the rehabilitated concrete structures are discussed by Kaiser and Karbhari [4].

\section{B. FRP Physical and Mechanical Properties}

The properties of prefabricated FRP system depend primarily on the source material of FRP. Such properties must be tested for acceptance before application. Physical and mechanical properties should be determined experimentally for in-place FRP system. In case of prefabricated FRP systems the gross area including fiber and polymer should be considered. Table-I presents some mechanical properties of GFRP and Carbon Fiber Reinforced Polymers (CFRP) at a fiber volume fraction of $50 \%$ as prescribed in the (ECP) [2].

Table-I: Mechanical Properties of FRP Laminates [2]

\begin{tabular}{|c|c|c|}
\hline Type of Fibers/Polymer & Glass-E / Ester Vinyl & Carbon / Epoxy \\
\hline $\begin{array}{l}\text { Longitudinal Tensile } \\
\text { Strength }\left(\mathrm{N} / \mathrm{mm}^{2}\right)\end{array}$ & 610 & 1448 \\
\hline $\begin{array}{l}\text { Transverse Tensile } \\
\text { Strength }\left(\mathrm{N} / \mathrm{mm}^{2}\right)\end{array}$ & 49 & 52 \\
\hline Shear Strength $\left(\mathrm{N} / \mathrm{mm}^{2}\right)$ & 16 & 93 \\
\hline $\begin{array}{l}\text { Longitudinal Modulus of } \\
\text { Elasticity }\left(\mathrm{N} / \mathrm{mm}^{2}\right)\end{array}$ & 54 & 181 \\
\hline $\begin{array}{l}\text { Transversal Modulus of } \\
\text { Elasticity }\left(\mathrm{N} / \mathrm{mm}^{2}\right)\end{array}$ & 14 & 10 \\
\hline $\begin{array}{c}\text { Shear Modulus of } \\
\text { Elasticity }\left(\mathrm{N} / \mathrm{mm}^{2}\right)\end{array}$ & 5 & 7 \\
\hline
\end{tabular}

\begin{tabular}{l|r} 
Poisson's Ratio & 0.25
\end{tabular}

0.3

\section{Ultrasonic Pulse Velocity Test}

Ultrasonic testing is one of the ten NDT methods described in ACI applicable for testing FRP-concrete bond condition. Different non-destructive methods have been developed to evaluate the quality of the FRP/concrete adhesive bond, based on ultrasonic waves, microwave, impact-echo, infrared thermography or a coupling of these two latter techniques [5].

Kundu et. al. [6] reported the detection of delaminations between concrete and glass FRP plates by the ultrasonic method. Bastianini, et. al. [7] used the ultrasonic technique: however, they utilized the amplitude of the reflection signal rather than the time delay for detecting the bond defects. The method was successful in assessment of the bond in FRP strengthened concrete, and masonry. Luprano, et. al. [8] employed the ultrasonic method for the characterization of the interface between FRP composites and concrete. Their work involved evaluation of the influence of carbon FRP materials and the thickness of the reinforcement on the defects. Ultrasonic test results were compared with the results obtained by infrared thermography. In the rehabilitation of a concrete bridge with carbon FRP sheets, the acousto-ultrasonic NDT technology has shown the ability to detect and image the delaminations between FRP sheet and concrete substrate [9]. The defects, in the form of delaminations, were intentionally formed at the FRP-concrete interface during installation of the FRP sheet to investigate the capability of this technique. The propagation $\mathrm{p}$-wave velocity $\left(\mathrm{C}_{\mathrm{p}}\right)$ in concrete ranges from 3000 to $5000 \mathrm{~m} / \mathrm{s}$ depending on composition of concrete, age, and condition, reduces to 2000 to $3000 \mathrm{~m} / \mathrm{s}$ for poor quality concrete [10]. Carino, et. al. [5] recommended that the wave velocity obtained from ultrasonic pulse-velocity measurements was more than this obtained from the impact-echo method and recommended using a specific method for p-wave velocity measurement using ultrasonic pulse-velocity. Martin and Forde [11] found that there was no difference between the velocity measurements from the two methods explaining that the reason was due to the low ultrasonic excitation frequency used compared to the commonly $100 \mathrm{kHz}$ frequency used.

\section{D.Correlation between Concrete Quality and Propagation Velocity}

The variation in wave velocity through testing a concrete member, can be compared, to assess condition and quality of concrete. The acceptable variation in p-wave velocity of concrete was calculated to be about 2 to $2.5 \%$. This is based on an average variation in concrete member strength equal to $7.8 \%$ for laboratory conditions and $9.5 \%$ for field conditions per ASTM standard [12]. The relation between age of concrete and wave velocity for different grades of concrete has been studied by Amir (1988), it is recommended that wave velocity increases with age for all concrete grades. Billington, et. al. [13] used the measurements of wave velocity to assess concrete quality and found that crack propagation of measurement points, not necessarily underneath it, degrade the general concrete quality so reduces the wave velocity.

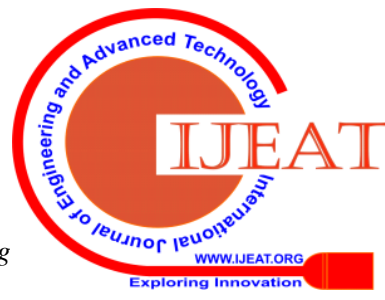


Pessiki and Johnson [14] experimentally verified the difference between wave velocities in a beam versus a core as shown in Fig. 1. From Fig. 1(a) it is shown that at strength of $30 \mathrm{MPa}$ the corresponding beam velocity is $4000 \mathrm{~m} / \mathrm{s}$ while in Fig. 1(b) at the same strength, the velocity is $3800 \mathrm{~m} / \mathrm{s}$ which is exactly 5\% difference. Lee, et. al. [15] investigated that the strength-velocity relationship of normal strength concrete is noticeably different from that of high strength concrete.

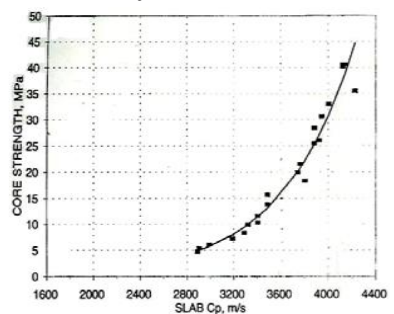

a) Core Strength vs Beam Velocity

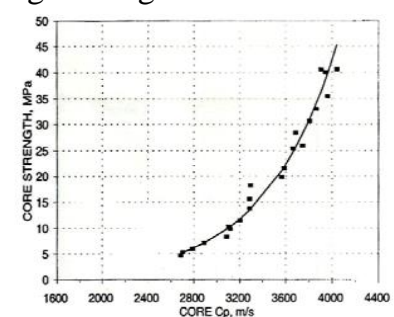

b) Core Strength vs Core Velocity
Fig. 1. Strength vs Velocity Relationships [14]

\section{E. Bond Quality at Internal Interfaces}

In FRP-strengthened beams failure may occur due to beam shear, flexural compression, FRP rupture, FRP debonding or concrete cover ripping as presented by Ascione, et. al. [16], and Bonacci and Maalej [17]. Based on experimental results conducted by Chen and Teng [18], the most common failure mode is due to debonding of FRP or ripping of the concrete cover. These failure modes are undesirable because the FRP cannot be fully utilized. In addition, such premature failures are generally associated with the reduction in deformability of the strengthened members. Premature failure modes are caused by interfacial shear and normal stress concentration at FRP cut off points and at flexural cracks along the beam [18].

Ultrasonic pulse-velocity studies of layered structures, such as repair works made to concrete structures led to the need to understand how bond quality at an interface between two materials affect the response.

Sansalone and Streett [19] studied the quality of repairs made to concrete box girders, repair done using concrete identical to the parent concrete. Test was carried to determine how well bonded these patches to concrete, P-wave velocity in concrete was $4060 \mathrm{~m} / \mathrm{s}$.

\section{EXPERIMENTAL PROGRAM}

The experimental program carried out in this research work is divided into three tasks; 1: GFRP laminates manufacture, 2: Preparation of the test specimens and, finally, 3: Beam load-testing and application of NDE test. Detailed description of each task is presented in the following sections.

\section{A. Manufacture of GFRP Laminates}

The dry lay-up technique was adopted using two directional GFRP sheets. These sheets are made of fibers predominantly at an angle used to cover the structural element. Installation on the concrete surface requires saturating resin usually after a primer has been applied, dry FRP sheets can be applied directly into the resin which has been applied uniformly onto the concrete surface. Additional resin applied onto the surface of FRP sheets in order to assure full saturation of the fibers with the resin. The properties of the materials used and the details of manufacture of the laminates is presented in the following sub-sections.

\section{Materials}

\section{Glass Fibers}

One roll of GFRP sheet was used, of $1.5 \mathrm{~m}$ wide by $50 \mathrm{~m}$ long. The sheet was cut into layers of beams cross sectional surface area $150 \mathrm{~mm}$ x $750 \mathrm{~mm}$ to cover each sample soffit as shown in Fig. 2.

Fiber glass with uniform linear density of $15 \mathrm{~N} / \mathrm{m}^{3}$ was used to strengthen the beams. Layers of sheets were stacked at different relative orientation angles. Varying the orientation angle between every two GFRP sheets was between $30^{\circ}$ and $45^{\circ}$. The layout of the fiber sheets was as follows:

3-layer sheets with angles of $90^{\circ} / 45^{\circ} / 90^{\circ}$.

5-layer sheets with angles of $60^{\circ} / 30^{\circ} / 0^{\circ} / 30^{\circ} / 60^{\circ}$.

7-layer sheets with angles of $90^{\circ} / 60^{\circ} / 30^{\circ} / 0^{\circ} / 30^{\circ} / 60^{\circ} / 90^{\circ}$.

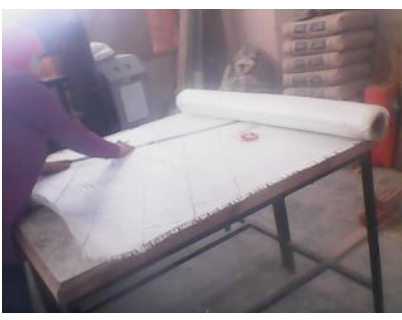

a) Measuring the angles

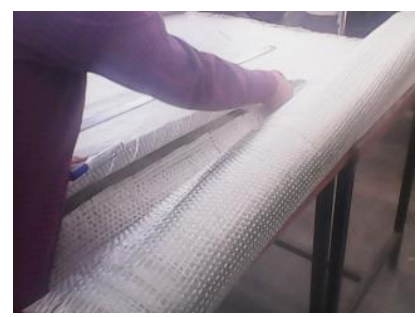

b) Final Cut
Fig. 2. The Glass fiber roll

Resin

The resin used is polyester DAN-1000 NT mixed with cobalt. The polyester comes in metallic drums weighting 20 $\mathrm{kg}$. DAN-100 NT is a medium reactive unsaturated polyester resin based on phthalic anhydride, with excellent and super laminating properties. It impregnates the fiber glass quickly and the laminate gives a smooth tack-free surface due to the presence of wax. It is liquid if it is not mixed with peroxide. The use of the polyester mixed with a small portion of peroxide accelerates the process of hardening under normal room temperature.

\section{Determination of Tensile Strength and Young's Modulus of the GFRP Laminates}

Three specimens were taken from every category with average width of $30 \mathrm{~mm}$. The total specimen length was about $300 \mathrm{~mm}$ including the length of the steel grips. Each sample thickness was accurately measured by a vernier. Samples end were supported by two side wooden supports to prevent sample slippage. Fig. 3 shows the test setup for the GFRP laminate samples.

All specimens were tested up to failure. The strains were calculated by dividing the recorded extensions at uniform intervals of load by the original specimen length. Thus, the stress-strain relationship was plotted for each sample to determine the modulus of elasticity for each specimen $\left(E_{f}\right)$. 


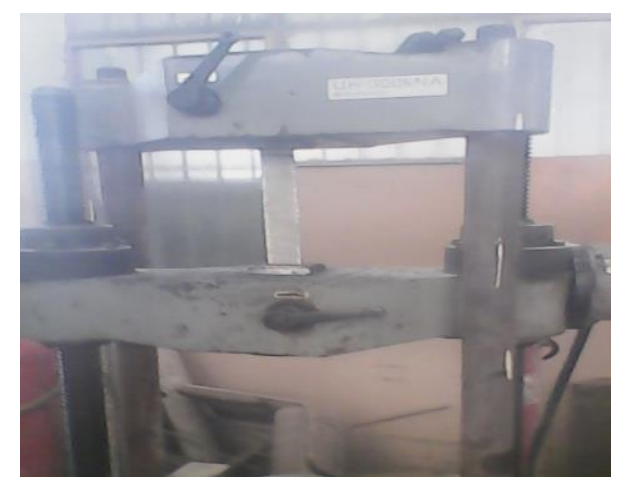

Fig. 3: Test Setup for GFRP Laminate Samples

The stress-strain curves of the used GFRP laminate samples are shown in Fig. 4. It is shown from Fig. 4, that the laminates exhibited linear behavior with no yielding up to failure. From Fig. 4, it is shown that samples with greater number of layers attained greater capacity and higher strain level. The results of the stress-strain curves of GFRP laminates are acceptable as per the ACI code [20] where it was stated that the relationship is expected to follow a linear trend.

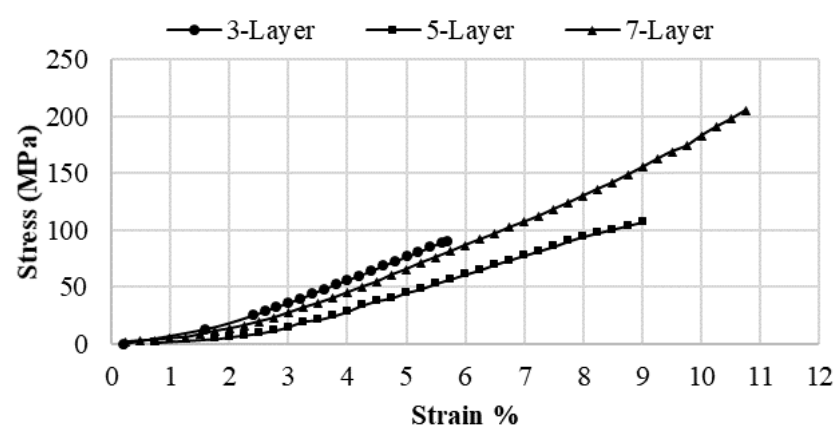

Fig. 4: Stress vs Strain Relationship for GFRP Laminates with Different Number of Layers

Table-II presents a summary of the mechanical properties obtained from the tensile tests performed on the samples.

Table-II: Mechanical Properties of GFRP Laminates

\begin{tabular}{|c|c|c|c|c|c|}
\hline $\begin{array}{c}\text { No. } \\
\text { Layers }\end{array}$ & $\begin{array}{c}\text { Laminate } \\
\text { Thickness } \\
(\mathbf{m m})\end{array}$ & $\begin{array}{c}\text { Average } \\
\text { Volume } \\
\text { Fraction } \\
\left(\mathbf{V}_{\mathbf{f}} \mathbf{\%}\right.\end{array}$ & $\begin{array}{c}\text { Max. } \\
\text { Tensile } \\
\text { Strength } \\
\mathbf{( M P a )}\end{array}$ & $\begin{array}{c}\mathbf{E} \\
\mathbf{( M P a )}\end{array}$ & $\begin{array}{c}\text { Max. } \\
\text { Strain } \\
\mathbf{\%}\end{array}$ \\
\hline 3 & 2.5 & 50 & 90.9 & 1901.5 & 5.7 \\
\hline 5 & 3.0 & 52 & 107.2 & 1523.8 & 9.0 \\
\hline 7 & 3.5 & 53 & 205.0 & 2154.2 & 10.8 \\
\hline
\end{tabular}

\section{B. Preparation of Test Specimens}

Three groups of beams constitute the experimental program test specimens. The beams were plain concrete 750 $\mathrm{mm}$ long with a square cross section $150 \mathrm{~mm} \times 150 \mathrm{~mm}$. The beams were strengthened by GFRP laminates with three different aspects: compressive strength, number of GFRP laminate layers and percentage of voids at the interface between FRP laminates and concrete. A total of ninety beam specimens were tested, of which, nine control specimens were constructed for each different concrete characteristic compressive strength. Then, eighty-one specimens were constructed to perform the parametric study which is summarized in Table-III. In addition, fifteen standard cubes and fifteen standard cylinders were cast for every concrete strength group of beams for a total of forty-five cubes and cylinders.

Table-III: Number of Test Specimens for Different Concrete Strength

\begin{tabular}{|c|c|c|c|c|c|c|c|c|c|c|c|}
\hline \multirow{2}{*}{$\begin{array}{c}\text { Group } \\
\text { No. }\end{array}$} & \multirow{2}{*}{$\begin{array}{c}\begin{array}{c}\text { No. of } \\
\text { Laminates }\end{array} \\
\% \text { Voids } \\
\end{array}$} & \multicolumn{3}{|c|}{3 Layers } & \multicolumn{3}{|c|}{5 Layers } & \multicolumn{3}{|c|}{7 Layers } & \multirow{2}{*}{$\begin{array}{c}\text { Total } \\
\text { No. }\end{array}$} \\
\hline & & 0 & 30 & 60 & 0 & 30 & 60 & 0 & 30 & 60 & \\
\hline A & $38 \mathrm{MPa}$ & 3 & 3 & 3 & 3 & 3 & 3 & 3 & 3 & 3 & 27 \\
\hline B & $45 \mathrm{MPa}$ & 3 & 3 & 3 & 3 & 3 & 3 & 3 & 3 & 3 & 27 \\
\hline C & $50 \mathrm{MPa}$ & 3 & 3 & 3 & 3 & 3 & 3 & 3 & 3 & 3 & 27 \\
\hline
\end{tabular}

\section{Concrete Design Mixes}

Three different concrete design mixes were used for each group of specimens. The materials weight per one cubic meter are listed for all groups in Table-IV.

\section{Table-IV: Concrete Design Mixes for All Specimen}

\begin{tabular}{|c|c|c|c|c|}
\hline $\begin{array}{c}\text { Group } \\
\text { No. }\end{array}$ & $\begin{array}{c}\text { Dolomite } \\
\left(\mathbf{k N} / \mathbf{m}^{3}\right)\end{array}$ & $\begin{array}{c}\text { Sand } \\
\left(\mathbf{k N} / \mathbf{m}^{3}\right)\end{array}$ & $\begin{array}{c}\text { Cement } \\
\left(\mathbf{k N} / \mathbf{m}^{3}\right)\end{array}$ & $\begin{array}{c}\text { Water } \\
\left(\mathbf{L i t} / \mathbf{m}^{3}\right)\end{array}$ \\
\hline A & 13.25 & 7.85 & 3.90 & 210 \\
\hline B & 12.20 & 7.15 & 4.20 & 210 \\
\hline C & 11.80 & 6.90 & 4.45 & 210 \\
\hline
\end{tabular}

\section{Determination of Concrete Compressive Strength}

The compressive strength of concrete was determined by compression tests carried out on standard cubes and cylinders. For all concrete beam groups 15 cubes and 15 cylinders were taken from the batch. All cubes and cylinders were tested after 28 days to determine and verify the design strength for all beam groups. Table-V shows a summary of the compression test results. From Fig. 5 it is observed that the strength ratio is almost constant for all concrete groups of different strength and lies within the acceptable known range.

Table-V: Cube and Cylinder 28-Day Compressive Strength for All Beam Groups

\begin{tabular}{|c|c|c|c|}
\hline Group No. & $\begin{array}{c}\text { Cube Strength } \\
\boldsymbol{f}_{\text {cu }} \text { (MPa) }\end{array}$ & $\begin{array}{c}\text { Cylinder Strength } \\
\boldsymbol{f}_{c}(\mathbf{M P a})\end{array}$ & $\begin{array}{c}\text { Strength Ratio } \\
\boldsymbol{f}_{\boldsymbol{c}}^{\prime} / \boldsymbol{f}_{\boldsymbol{c u}}\end{array}$ \\
\hline A & 38.8 & 34.3 & 0.88 \\
\hline B & 45.7 & 39.8 & 0.87 \\
\hline C & 50.7 & 44.7 & 0.88 \\
\hline
\end{tabular}

\section{Applying Intentional Delaminations (\% Voids)}

Several double-faced adhesive tapes, each, of area $45 \mathrm{~mm} \mathrm{x}$ $50 \mathrm{~mm}$ were applied at the concrete beam soffit to simulate a debonded area between first layer of GFRP laminate and concrete. Thus, fifteen randomly dispersed tapes were used to cover $30 \%$ of concrete beam soffit while, thirty were used to cover $60 \%$ of the soffit. Fig. 5 presents the application of the adhesive tapes for \% void achievement.

\section{Determination of Concrete Wave Velocity}

As well as measuring compressive strength of standard cubes and cylinders, the p-wave velocity $\left(C_{p}\right)$ through the standard specimens was measured to determine the expected wave velocity through the beam specimens.

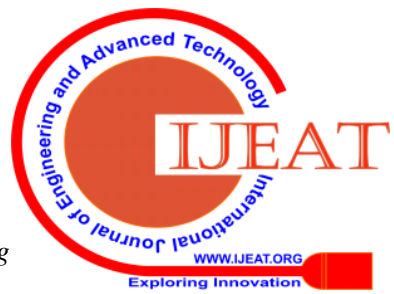


In addition, the measurement would serve to verify if the UPV equipment would be sensitive to the change in specimen shape.

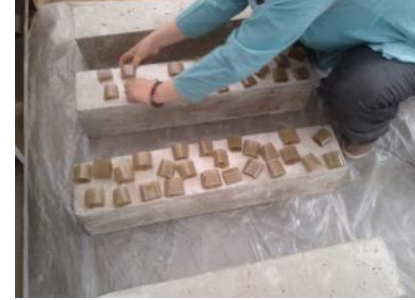

a) Applying Adhesive Tape

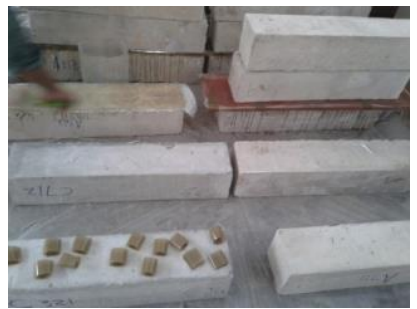

b) Laminate Layup
Fig.5: Delamination Simulation by Adhesive Application

Fig. 6 presents examples of the wave velocity measurement setup on the different samples. Further, a summary of the obtained results is presented in Table-VI. From Table-VI it is proven that the UPV equipment was sensitive enough to differentiate between the different geometry of the specimens. It is worth noting that the average values are within the known range with respect to the compressive strength.

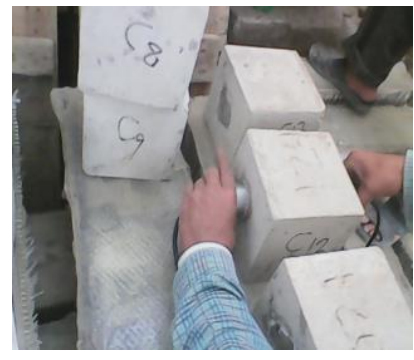

a) Cube $\mathrm{C}_{\mathrm{p}}$ Measurement

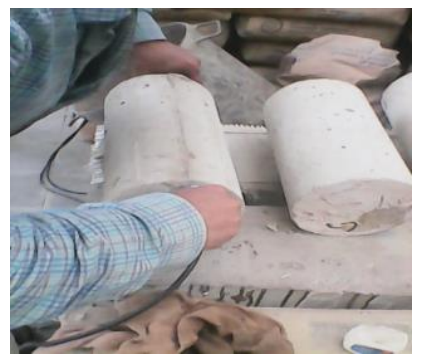

b) Cylinder $\mathrm{C}_{\mathrm{p}}$ Measurement
Fig.6: Measuring Ultrasonic Wave Velocity through Cubes and Cylinders

Table-VI: Cube and Cylinder Ultrasonic Wave Velocity for All Beam Groups

\begin{tabular}{|c|c|c|}
\hline Group No. & $\begin{array}{c}\text { Cube Velocity } \\
\mathbf{C p}_{\mathbf{c u}} \mathbf{( m / s )}\end{array}$ & $\begin{array}{c}\text { Cylinder Velocity } \\
\mathbf{C p}_{\mathbf{c}}(\mathbf{m} / \mathbf{s})\end{array}$ \\
\hline A & 4508 & 4022 \\
\hline B & 4976 & 4113 \\
\hline C & 5059 & 4796 \\
\hline
\end{tabular}

\section{Beam Test Setup for Load Test and NDE Test}

\section{Load Testing}

All beams were tested under 4-point load concurrently with the non-destructive test using the UPV, Fig. 7 shows a schematic of the load test setup. Fig. 8 presents a complete picture of the testing setup. Beam specimens were tested under a monotonic load at a rate of $1 \mathrm{kN} / \mathrm{min}$.

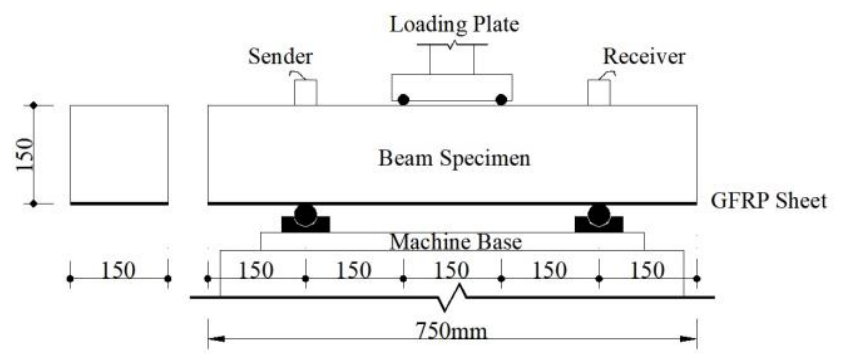

Fig. 7: Beam Testing Setup

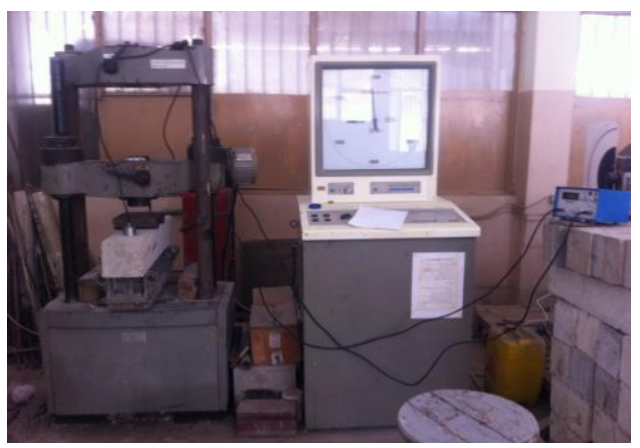

Fig. 8: Actual Load Testing Setup

\section{NDE Testing}

The system consisted of a calibrated ultrasonic pulse velocity device used to measure ultrasonic pulse wave velocity (UPV) during loading as shown from Fig. 8. The UPV transmitter and receiver were located $450 \mathrm{~mm}$ apart on the top face of the tested beam and centered around the loading plate as shown in Fig. 7. The travel time of the UPV pulses were recorded at each loading step from the testing machine with an accuracy of $0.1 \mu \mathrm{s}$. The distance between the UPV poles was then divided by the recorded travel time to determine the velocity at each loading step.

\section{RESULTS AND DISCUSSION}

All beam specimens were tested after 28 days of casting. All specimens were loaded and the appearance of first crack, cracking load, crack propagation, ultimate load and mode of failure were observed. The recorded measurements are; machine load, mid-span deflection and the UPV travel time reading. The results of the monotonic loading tests performed concurrently with UPV testing on the beam specimens are presented and discussed in the following sections. The discussion will focus on four major parameters in the following sections which are:

- Cracking and failure loads

- Load vs mid-span deflection relationships

- Strength vs UPV relationships

- Stiffness improvement index

\section{A. The Cracking and Failure Loads}

For all tested beams, the first crack appeared in beam soffit at the midspan between the two load heads coupled with an excessive increase in deflection. Those flexural cracks appeared when the total load of the beam reached between 35 and $40 \mathrm{kN}$ for Group (A), between 40 and $45 \mathrm{kN}$ for Group (B) and between 45 and $50 \mathrm{kN}$ for Group (C).

Cracks initiated during the loading intervals and did not propagate with loading. Two factors contributed to that; existence of GFRP laminates used in strengthening the beams and the beam span to depth ratio, which prevented the beam failure in flexural mode.

Tables-VII through $\mathrm{X}$ show all test results of which cracking loads, failure loads and maximum deflection for each tested beam, it was observed that cracks started to propagate through the $150 \mathrm{~mm}$ (distance between the two loading line loads) until failure. 
Table-VII: Summary of Test Results on 3-Layer Beams

\begin{tabular}{|c|c|c|c|c|}
\hline Beam ID & \% Voids & $\mathbf{P}_{\mathbf{c}} \mathbf{( k N )}$ & $\mathbf{P}_{\mathbf{f}} \mathbf{( k N )}$ & $\boldsymbol{\Delta}_{\max }(\mathbf{m m})$ \\
\hline A 31 & 0 & 38.5 & 55.0 & 3.9 \\
\hline A 32 & 30 & 41.0 & 39.2 & 2.4 \\
\hline A 33 & 60 & 25.3 & 30.0 & 2.4 \\
\hline \hline B 31 & 0 & 37.9 & 82.4 & 6.6 \\
\hline B 32 & 30 & 45.8 & 76.0 & 5.6 \\
\hline B 33 & 60 & 43.0 & 52.5 & 3.9 \\
\hline \hline C 31 & 0 & 45.0 & 81.0 & 6.0 \\
\hline C 32 & 30 & 43.0 & 79.0 & 5.8 \\
\hline C 33 & 60 & 40.5 & 50.0 & 3.4 \\
\hline
\end{tabular}

Table-VIII: Summary of Test Results on 5-Layer Beams

\begin{tabular}{|c|c|c|c|c|}
\hline Beam ID & \% Voids & $\mathbf{P}_{\mathbf{c}} \mathbf{( k N )}$ & $\mathbf{P}_{\mathbf{f}} \mathbf{( k N )}$ & $\boldsymbol{\Delta}_{\max } \mathbf{( m m )}$ \\
\hline A 51 & 0 & 33.5 & 60.0 & 4.2 \\
\hline A 52 & 30 & 34.5 & 42.7 & 3.7 \\
\hline A 53 & 60 & 27.5 & 31.5 & 2.3 \\
\hline \hline B 51 & 0 & 44.0 & 84.0 & 6.3 \\
\hline B 52 & 30 & 43.0 & 79.0 & 4.6 \\
\hline B 53 & 60 & 40.0 & 59.0 & 3.9 \\
\hline \hline C 51 & 0 & 57.0 & 98.0 & 6.2 \\
\hline C 52 & 30 & 46.0 & 81.0 & 5.3 \\
\hline C 53 & 60 & 40.0 & 73.0 & 4.7 \\
\hline
\end{tabular}

Table-IX: Summary of Test Results on 7-Layer Beams

\begin{tabular}{|c|c|c|c|c|}
\hline Beam ID & \% Voids & $\mathbf{P}_{\mathbf{c}}(\mathbf{k N})$ & $\mathbf{P}_{\mathbf{f}}(\mathbf{k N})$ & $\boldsymbol{\Delta}_{\mathbf{m a x}}(\mathbf{m m})$ \\
\hline A 71 & 0 & 48.0 & 87.5 & 4.7 \\
\hline A 72 & 30 & 50.5 & 74.1 & 4.9 \\
\hline A 73 & 60 & 43.2 & 51.5 & 3.4 \\
\hline \hline B 71 & 0 & 41.5 & 114.0 & 5.2 \\
\hline B 72 & 30 & 50.8 & 86.0 & 5.3 \\
\hline B 73 & 60 & 40.7 & 60.0 & 3.3 \\
\hline \hline C 71 & 0 & 55.0 & 121.0 & 5.5 \\
\hline C 72 & 30 & 53.0 & 102.5 & 5.8 \\
\hline C 73 & 60 & 48.0 & 87.5 & 5.1 \\
\hline
\end{tabular}

Table-X: Summary of Test Results on Control Beams

\begin{tabular}{|c|c|c|}
\hline Beam ID & $\mathbf{P}_{\mathbf{f}}(\mathbf{k N})$ & $\boldsymbol{\Delta}_{\max }(\mathbf{m m})$ \\
\hline A control & 26.5 & 2.2 \\
\hline B control & 33.0 & 1.4 \\
\hline C control & 44.0 & 1.7 \\
\hline
\end{tabular}

From all the previous tables it is observed that in all specimens the deflections increased linearly with increasing load prior to first cracking. First cracking during the test was pointed in the load deflection curve by a marked reduction in the stiffness. The initial crack occurred under the concentrated line loads or within its close vicinity. New flexural cracks were developed closer to the supports while the existing cracks grew with increasing load. In a few numbers of tested beams, the cracks were vertical during early stages of loading but propagated diagonally towards the concentrated loads as the load was further increased. In general, all tested beams experienced brittle failure.

\section{B. Load vs Midspan Deflection Relationship}

The beams strengthened with GFRP laminates showed typical load vs deflection relationship. The relationship considered of a bilinear curve: stiff up to the cracking load, and then softens when concrete cracks, but becomes also linear up to failure. Fig. 9 presents an example of the load vs deflection for Group A beams strengthened by 7 layers of GFRP laminates with delaminations (\% voids) 0,30 and $60 \%$ respectively. From Fig. 9 it is observed that the beam with
$0 \%$ voids failed at higher load and the first crack occurred at higher deflection. All strength groups showed a similar response as that followed by beams of Group A. In the following subsections the effect delamination (\% voids) and the effect of number of laminate layers on load and deflection of the beams will be presented for each concrete strength group.

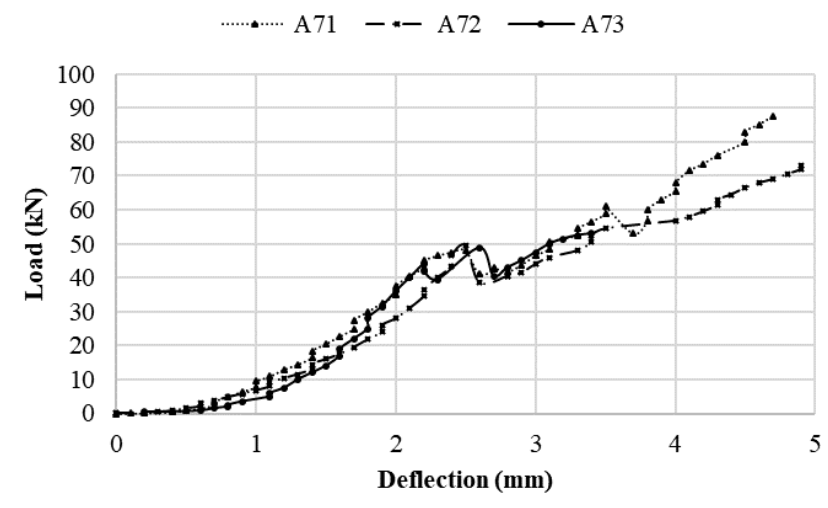

Fig. 9: Load vs Deflection Relationship for 7-Layer Strengthened Beams with Various \% Delaminations For Group A (38 MPa Strength)

Fig. 10 presents Group A comparisons between load-carrying capacity with number of layers and \% voids in contrast to the control beam. From Fig. 10 it is shown that strengthening using 3-layer GFRP laminates with 0\%, 30\%, and $60 \%$ of voids increased the capacity by $2.08,1.48,1.13$ times, respectively, from that of the control beam. While, strengthening using 5-layer GFRP laminates with 0\%, 30\%, and $60 \%$ of voids increased the capacity by $2.26,1.61,1.19$ times, respectively. Finally, strengthening using 7-layer GFRP laminates with $0 \%, 30 \%$, and $60 \%$ of voids increased the capacity by 3.30, 2.80, 1.94 times, respectively.

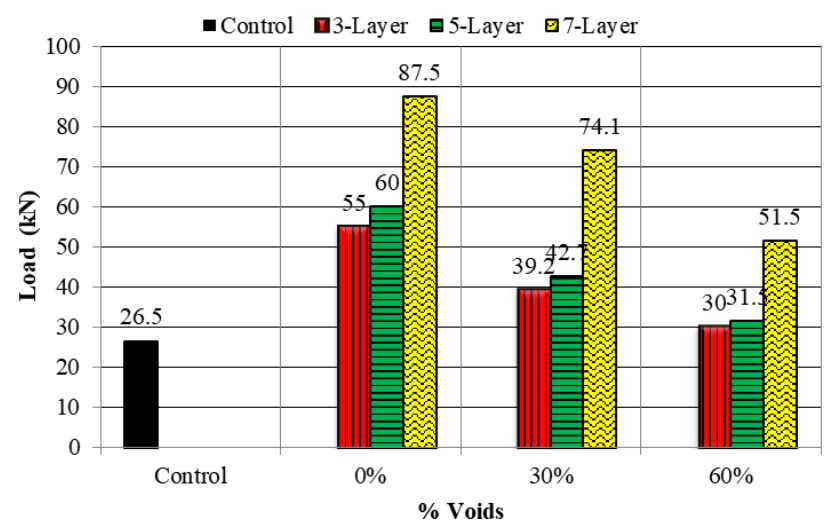

Fig. 10: Load-Carrying Capacity for Group A Beams with Different Number of Layers vs \% Voids

\section{For Group B (45 MPa Strength)}

Fig. 11 presents Group B comparisons between load-carrying capacity with number of layers and \% voids in contrast to the control beam. From Fig. 11 it is shown that strengthening using 3-layer GFRP laminates with 0\%, 30\%, and $60 \%$ of voids increased the capacity by $2.5,2.3,1.59$ times, respectively, from that of the control beam. While, strengthening using 5-layer GFRP laminates with 0\%, 30\%, and $60 \%$ of voids increased the capacity by $2.55,2.4,1.79$ times, respectively.

Finally,

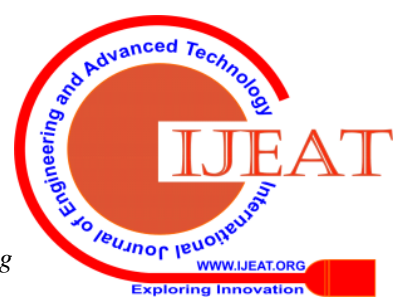


strengthening using 7-layer GFRP laminates with 0\%, 30\%, and $60 \%$ of voids increased the capacity by $3.45,2.6,1.82$ times, respectively.

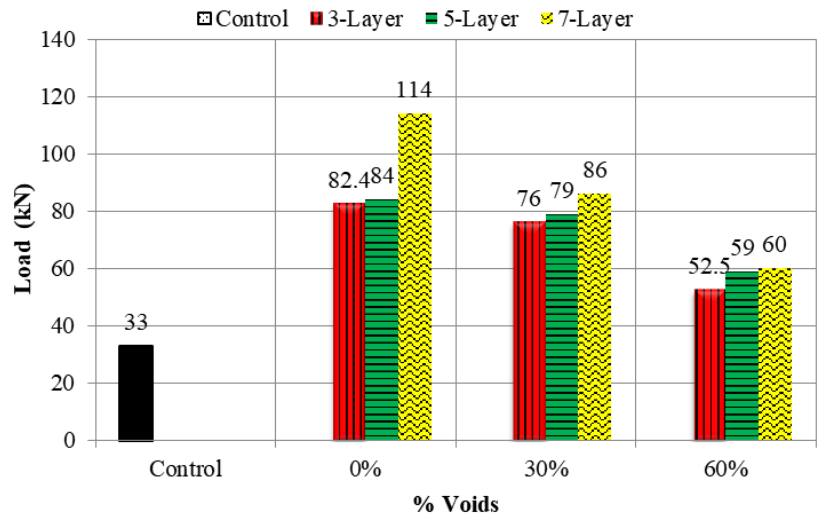

Fig. 11: Load-Carrying Capacity for Group B Beams with Different Number of Layers vs \% Voids

\section{For Group C (50 MPa Strength)}

Fig. 12 presents Group C comparisons between load-carrying capacity with number of layers and \% voids in contrast to the control beam. From Fig. 12 it is shown that strengthening using 3-layer GFRP laminates with 0\%, 30\%, and $60 \%$ of voids increased the capacity by $1.84,1.8,1.14$ times, respectively, from that of the control beam. While, strengthening using 5-layer GFRP laminates with 0\%, 30\%, and $60 \%$ of voids increased the capacity by $2.23,1.84,1.66$ times, respectively. Finally, strengthening using 7-layer GFRP laminates with $0 \%, 30 \%$, and $60 \%$ of voids increased the capacity by $2.75,2.33,1.99$ times, respectively.

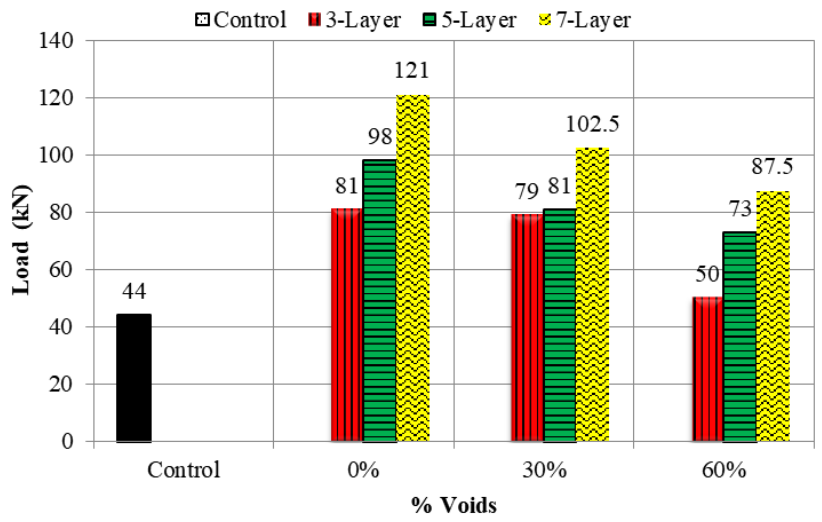

Fig. 12: Load-Carrying Capacity for Group C Beams with Different Number of Layers vs \% Voids

\section{Strength vs Ultrasonic Pulse Velocity Relationship}

The results obtained from ultrasonic testing in correlation with the concrete strength is presented for each beam group. Table- XI presents wave velocity for each beam group.

Table- XI: Wave Velocity through Beam Groups

\begin{tabular}{|c|c|c|c|c|}
\hline Group No. & $\begin{array}{c}\text { \% } \\
\text { Voids }\end{array}$ & $\begin{array}{c}\text { Group (A) } \\
\text { Wave } \\
\text { Velocity (m/s) }\end{array}$ & $\begin{array}{c}\text { Group (B) } \\
\text { Wave } \\
\text { Velocity (m/s) }\end{array}$ & $\begin{array}{c}\text { Group (C) } \\
\text { Wave } \\
\text { Velocity (m/s) }\end{array}$ \\
\hline $\begin{array}{c}\text { Control } \\
\text { Beam }\end{array}$ & N/A & $\mathbf{4 1 1 6}$ & $\mathbf{4 3 5 2}$ & $\mathbf{4 4 5 0}$ \\
\hline \hline Beam 31 & 0 & 4169 & 4401 & 4482 \\
\hline Beam 32 & 30 & 4046 & 4350 & 4367 \\
\hline Beam 33 & 60 & 3912 & 4299 & 4205 \\
\hline \hline Beam 51 & 0 & 4313 & 4453 & 4601 \\
\hline
\end{tabular}

Retrieval Number: C5170029320/2020@BEIESP

DOI: 10.35940/ijeat.C5170.029320

Journal Website: www.ijeat.org

\begin{tabular}{|c|c|c|c|c|}
\hline Beam 52 & 30 & 3934 & 4390 & 4597 \\
\hline Beam 53 & 60 & 3724 & 4104 & 4208 \\
\hline \hline Beam 71 & 0 & 4494 & 4707 & 4951 \\
\hline Beam 72 & 30 & 4028 & 4538 & 4763 \\
\hline Beam 73 & 60 & 4006 & 4219 & 4329 \\
\hline
\end{tabular}

From Table-XI by comparing wave velocities for all beam groups with different number of laminate layers it is observed that:

\section{For Group A (38 MPa Strength)}

Strengthening using 3-layer GFRP laminates with $0 \%$ voids, the wave velocity through tested beams increased by $1.3 \%$ than that of the control beam, but for $30 \%, 60 \%$ it was reduced by $1.7 \%$ and $4.9 \%$, respectively. While for strengthening using 5-layer GFRP laminates with $0 \%$ voids, the wave velocity through tested beams increased by $4.8 \%$ than that of the control beam, but for $30 \%, 60 \%$ it was reduced by $4.4 \%$ and $9.5 \%$, respectively. Finally, strengthening using 7-layer GFRP laminates with $0 \%$ voids, the wave velocity through tested beams increased by $9.2 \%$ than that of the control beam, but for $30 \%, 60 \%$ it was reduced by $2.1 \%$ and $2.7 \%$, respectively.

\section{For Group B (45 MPa Strength)}

Strengthening using 3-layer GFRP laminates with $0 \%$ and $30 \%$ voids, the wave velocity increased by $1.2 \%$ and $0.1 \%$, respectively, than that of the control beam, but for $60 \%$ it was reduced by $1.2 \%$. While for strengthening using 5-layer GFRP laminates with $0 \%$ and $30 \%$ voids, the wave velocity increased by $2.4 \%$ and $0.9 \%$, respectively, that of the control beam, but for $60 \%$ it was reduced by $5.6 \%$. Finally, strengthening using 7-layer GFRP laminates with $0 \%$ and $30 \%$ voids, the wave velocity increased by $8.2 \%$ and $4.3 \%$, respectively, than that of the control beam, but for $60 \%$ it was reduced by $3.0 \%$.

\section{For Group C (50 MPa Strength)}

Strengthening using 3-layer GFRP laminates with $0 \%$ voids increases the wave velocity through tested beams $0.8 \%$ than that of the control beam, but for $30 \%, 60 \%$ it was reduced by $1.8 \%$, and $5.5 \%$ respectively. While for strengthening using 5-layer GFRP laminates with $0 \%$ and $30 \%$ voids, the wave velocity increased by $3.4 \%$ and $3.3 \%$, respectively, than that of the control beam, but for $60 \%$ it was reduced by $5.4 \%$. Finally, strengthening using 7-layer GFRP laminates with $0 \%$ and $30 \%$ voids, the wave velocity increased by $11.3 \%$ and $7.1 \%$, respectively, that of the control beam, but for $60 \%$ it was reduced by $2.7 \%$.

For a better visual representation of the previous results, Fig. 13 shows comparisons between wave velocities for all beam groups with different number of laminate layers and varying \%voids (delaminations). 


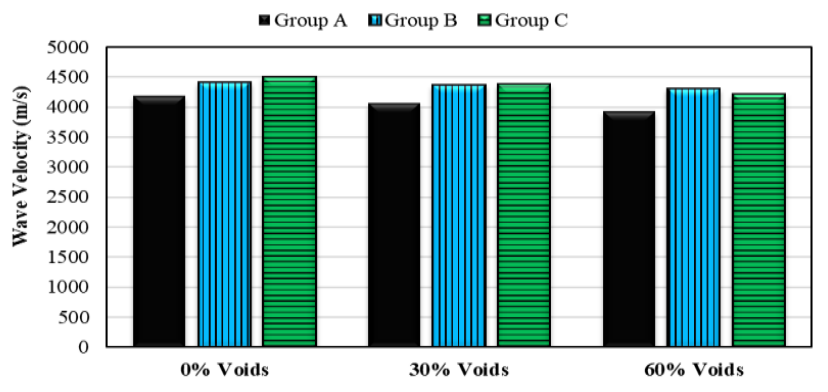

(a)

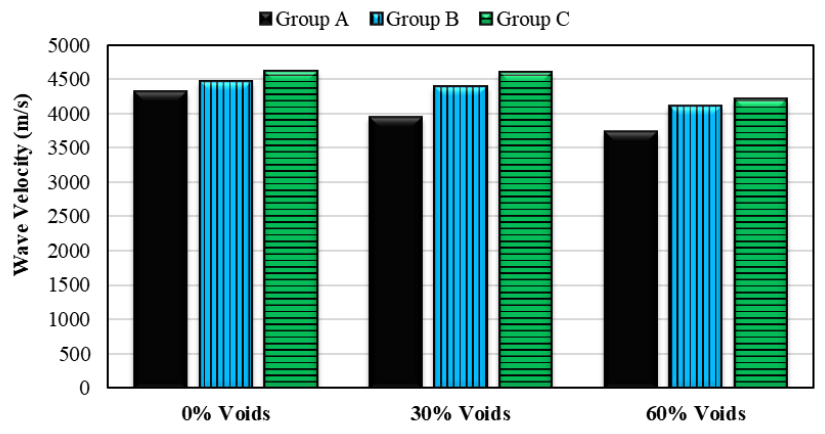

(b)

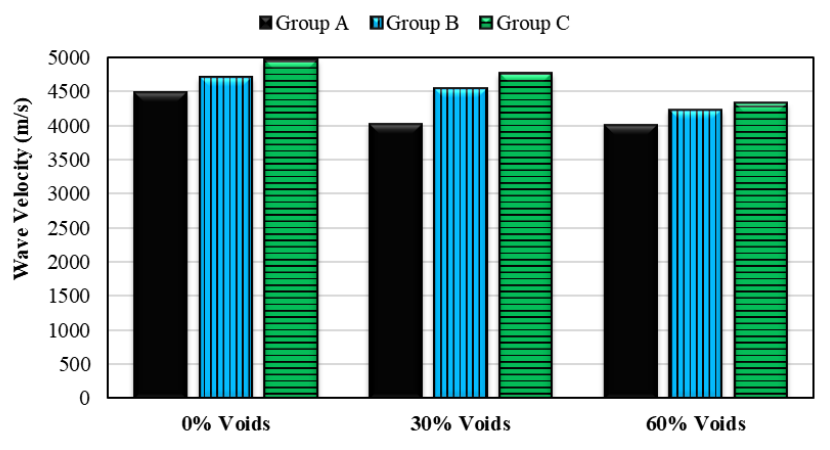

(c)

Fig. 13: Comparison between Wave Velocities for All Beam Groups; (a) 3-Layer, (b) 5-Layer, and (c) 7-Layer

From all the previous results presented in Table-XI and Fig. 13, it could be concluded that for the same strength and number of layers, as the \% delamination increased, the velocity of the wave is reduced. This is an indication of the degrading bond strength between concrete and the GFRP layers even more than that of the control beam. This could be explained by the fact that existence of the GFRP layers with voids on the beams soffit result in distorting the p-wave inside the beam and result in a reduction in the wave velocity.

On the other hand, for the same strength and \% delaminations, as the number of layers increased, the wave velocity increased. This is an indication of the increased system stiffness due to the bond action between concrete and GFRP. Finally, for the same number of layers and \% delaminations, as the concrete strength increased, the wave velocity increased. This observation is more significant with lower strength than that of lower strength.

By correlating the results obtained from the wave velocity measurements to the load-carrying capacity of the beams it is obvious that they are consistent. Where, for example, for the same strength beams with the same number of laminate layers, the increase in \% delaminations reduce the load carrying capacity and at the same time reduce the propagation wave velocity. However, it is important to note that rate of decrease in the capacity is not proportional to that of the wave velocity decrease. The reason for this would be that improvement in load-carrying capacity is due to the increase in flexural strength due to the bond between the GFRP and the concrete. While the increase in wave velocity is related to the increase in the material stiffness due to the confinement from the GFRP to the concrete at the interface.

\section{D.Stiffness Improvement Index}

From load-deflection curves the value of the stiffness of each beam is calculated as the slope of the first straight part of the load-deflection curve at value of load less than the observed cracking load.

Stiffness Improvement Index (SII) may be defined as the percentage of increase in deformation (from cracking stage to failure stage) relative to deformation at cracking stage:

Stiffness Improvement Index $=\frac{\delta_{\mathrm{ul}}-\delta_{\mathrm{cr}}}{\delta_{\mathrm{cr}}}$

Where,

$\delta_{\mathrm{uI}}=$ Midspan deflection at ultimate load

$\delta_{\mathrm{cr}}=$ Midspan deflection at first cracking load

Fig. 14 presents the stiffness improvement index relations for all beam groups. From Fig. 14 it is shown that the presence of a larger number of GFRP layers on the beam enhances the stiffness, thus the stiffness improvement index. In addition, from Fig. 14, it is noted that GFRP laminates are more effective with higher concrete strength as the fiber reinforcement mechanisms increase with the increase of the concrete strength, if fiber rupture is avoided.

\section{SUMMARY \& CONCLUSIONS}

The current study experimentally investigates the capacity of strengthened concrete beams with different number of layers of GFRP laminates in with varying \% delaminations represented by \% voids and contribution of both concrete and GFRP laminates in carrying load. The different parameters affecting the behavior of GFRP-strengthened plain concrete beams, namely; concrete characteristic strength, the number of laminate layers, and percentage of voids are investigated.

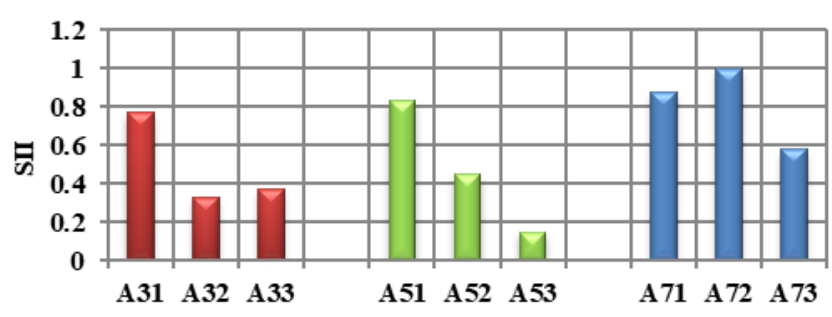

(a)

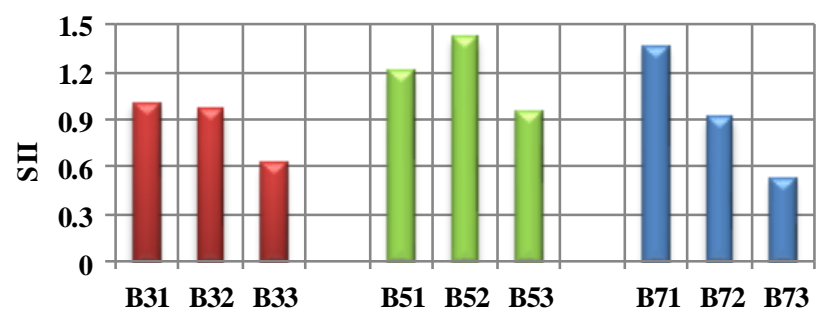

(b) 


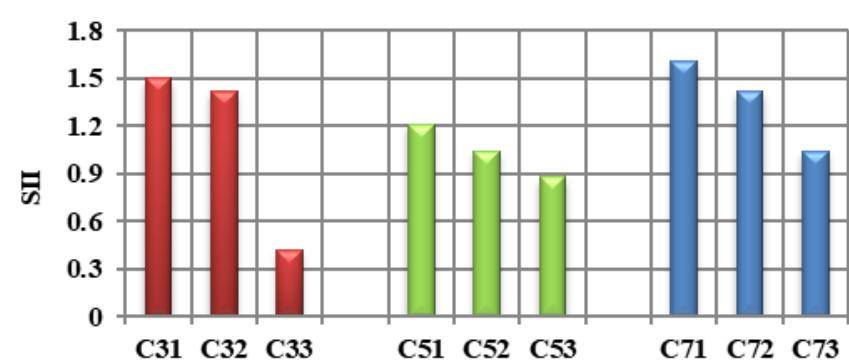

(c)

Fig. 14: Comparison between Stiffness Improvement Index for Tested Beams; (a) Group A, (b) Group B, and (c) Group C

The experimental program included ninety plain concrete beams. Three groups, each, of twenty-seven beams were strengthened by 3-layer, 5-layer, and 7-layer GFRP laminates with different \% voids. The behavior of the beams under load was studied along with a concurrent evaluation using UPV tests. The inclusion of glass fibers in all beam groups resulted in enhanced stiffness, stiffness improvement index and absorbed energy.

From the herein presented discussions of the obtained results, several conclusions could be drawn as follows:

1. The test results of the locally produced GFRP laminates showed a product with accepted material properties and high strength to weight ratio that could be applied effectively to strengthen concrete beams.

2. It was found that interfacial debonding in most cases initiates where a localized flexural crack formed in the concrete, weak cracks appear at interface, Then, it extends through the concrete adjacent to the bond interface.

3. As the percentage of voids decreased, the capacity of strengthened concrete beams increased with a semi linear variation relation enhancing behavior of beams and decreasing crack propagation.

4. The increase in number of GFRP laminate layers enhances the stiffness improvement index.

5. GFRP laminates are more effective with higher concrete strength provided that debonding is not present.

6. The UPV technique was sensitive to the variation in concrete strength and GFRP laminate layers. Where the p-wave velocity increased with concrete strength. Further, existence of more laminate layers at beam soffit increased the p-wave velocity at the interface.

7. The UPV technique showed changes in p-wave propagation pattern and velocity between different specimen shapes, (cubes, cylinders, and beams).

\section{REFERENCES}

1. Quiertant, M., 2013. "Strengthening Concrete Structures by Externally Bonded Composite Materials", Chapter 23, Organic Materials for Sustainable Construction, Editor, Yves Mouton, February, John Wiley \& Sons, Inc., ISBN 9781848212244, pp 503-527.

2. ECP 208-2005. Egyptian Standard Code Committee." The Use of Fiber Reinforced Polymer (FRP) in the Construction Fields"

3. ACI (2008), American Concrete Institute, "Building code requirements for reinforced concrete and commentary", Detroit.

4. H. Kaiser , V. M. Karbhari, 2003. "Identification of potential defects in the rehabilitation of concrete structures with FRP composites," International Journal of Materials and Product Technology Journal, Vol. 19, No. 6, April., pp.498 - 520. ISSN: 0268-1900

5. Carino, N.J., Sansalone, M., and Hsu. N.N., 1986(a). "Flaw Detection in Concrete by Frequency Spectrum Analysis of Impact-Echo

Waveforms," International Advances in Nondestructive Testing, Vol. 12, pp. 117-146.

6. Kundu, T., Ehsani, M., Maslov, K.I. and Guo, D. (1999), 'C-scan and L-scan generated images of the concrete/GFRP composite interface', NDT \& E International, 32, 61-69.

7. Bastianini, F., Tommaso, A.D. and Pascale, G. (2001), 'Ultrasonic non-destructive assessment of bonding defects in composite structural strengthenings', Composite Structures, 53(4), 463-467.

8. Vincenza A.M. LUPRANO, Antonella TUNDO, Brindisi Ermanno GRINZATO, S. MARINETTI, Paolo. G. BISON (2006), "Non-Destructive Defect Characterization in Civil Structures Reinforced by Means of FRP" Consiglio Nazionale Delle Ricerche, Padova, Italy, ECNDT 2006 - We.1.6.1, pp 1-9.

9. Ekenel $\mathrm{m}$, galati $\mathrm{n}$, myers $\mathrm{j} \mathrm{j}$, nanni a and godínez $\mathrm{v}$ (2005), 'Acousto-Ultrasonic Technology for Nondestructive Evaluation of Concrete Bridge Members Strengthened by Carbon Fiber-Reinforced Polymer,' Transportation Research Record, 1928, 245-251

10. Popovics, J.S. and Rose, J.L., 1994. "A Survey of Developments in Ultrasonic NDE of Concrete," IEEE Transactions of Ultrasonics, Ferroelectrics, and Frequency Control. Vol. 41, No. 1, January, pp 1-4.

11. Martin, J., and Forde, M.C., 1995. "Influence of Concrete Properties on Impulse Hammer Spectrum and Compression Wave Velocity," Construction and Building Materials, Vol. 9, No. 4, pp. 245-255.

12. ASTM C39/C39M-99, 1999. "Standard Test Method for Compressive Strength of Cylindrical Concrete Specimens," Annual Book of ASTM Standards, Vol. 04.02, ASTM, Pennsylvania, pp. 18-22.

13. Billington, E.D., Sack, D.A, and Olson, L.D., 2001. "Sonic Pulse Velocity Testing to Assess Condition of a Concrete Dam," ACI Technical Session, Philadelphia, PA, Mar. 3, pp. 1-12.

14. Pessiki, S. and Johnson, M.R., 1996. "Nondestructive Evaluation of Early-Age Concrete Strength in Plate Structures by the Impact-Echo Method," ACI Materials Journal, Vol. 93, No. 3, May-Jun., pp. 261-271.

15. Lee, H.K., Yim, H., and Lee, K.M., 2003. "Velocity-Strength Relationship of Concrete by Impact-Echo Method," ACI Materials Journal, Vol. 100, No. 1, Jan.-Feb., pp. 49-54.

16. Ascione, L., Berardi, V.P., and D'Aponte, A., 2012. "Creep Phenomena in FRP Materials," Journal of Mechanics Research Communications, Elsevier Ltd., Vol. 43, July., pp. 15-21.

17. Bonacci, J.F. and Maalej, M., 2001. "Behavioral Trends of RC Beams Strengthened with Externally Bonded FRP." ASCE Journal of Composites for Construction, Vol. 5, No. 2, May, pp 102-113.

18. Chen, J.F. and Teng, J.G., 2003. "Shear Capacity of FRP-Strengthened RC Beams: FRP Debonding." Journal of Construction and Building Materials, Elsevier Ltd., Vol. 17, No. 1, Feb., pp 27-41.

19. Sansalone, M.J. and Streett, W.B., 1997. "Impact-Echo, Nondestructive Evaluation of Concrete and Masonry," Bullbrier Press, Ithaca, NY, 339 pp.

20. ACI 440.1R-06, 2006. "Guide for the Design and Construction of Concrete Reinforced with FRP Bars," ACI, American Concrete Institute, Farmington Hills, MI., 42.

\section{AUTHORS PROFILE}

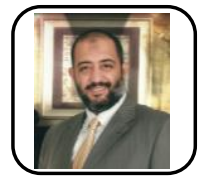

Waleed F. Tawhed is an Assistant Professor in Civil Engineering Department, Faculty of Engineering at Mataria, Helwan University, Cairo, Egypt. He has received his Ph.D. degree from the University of South Carolina, Columbia, USA in 2005. He is specialized in strength and properties of materials and Non-Destructive testing. His research interests include; behavior and construction of concrete materials, non-destructive evaluation and non-destructive testing of concrete and masonry materials, behavior and applications of modern composite materials in repair and strengthening of concrete structures, in addition to studying innovative techniques for recycling organic materials to be used in concrete structures. Dr. Tawhed is active in research and academic supervision on numerous engineering post-graduate students in the field of material science. 
Quality Assessment of Strengthened Concrete by FRP Laminates using Non-Destructive Testing

Yasmen R. Elsayed is a Teaching Assistant in Civil Engineering Department, Faculty of Engineering at Mataria, Helwan University, Cairo, Egypt. She is specialized in strength and properties of materials and Non-Destructive testing. Her research interests include; behavior and construction of concrete materials, use of advanced composite materials in repair and strengthening of concrete structures, applications of non-destructive techniques in evaluation of concrete structures. 